\title{
Anterior cervical discectomy and fusion performed using structural allograft or polyetheretherketone: pseudarthrosis and revision surgery rates with minimum 2-year follow-up
}

\author{
Minghao Wang, MD, PhD, ${ }^{1,2}$ Dean Chou, MD, ${ }^{1}$ Chih-Chang Chang, MD, ${ }^{1}$ Ankit Hirpara, BA, ${ }^{1}$ \\ Yilin Liu, MD, ${ }^{1}$ Andrew K. Chan, MD, ${ }^{1}$ Brenton Pennicooke, MD, ${ }^{1}$ and Praveen V. Mummaneni, MD' \\ 'Department of Neurological Surgery, University of California, San Francisco, California; and 2Department of Neurosurgery, \\ First Affiliated Hospital of China Medical University, Shenyang, China
}

\begin{abstract}
OBJECTIVE Both structural allograft and PEEK have been used for anterior cervical discectomy and fusion (ACDF). There are reports that PEEK has a higher pseudarthrosis rate than structural allograft. The authors compared pseudarthrosis, revision, subsidence, and loss of lordosis rates in patients with PEEK and structural allograft.

METHODS The authors performed a retrospective review of patients who were treated with ACDF at their hospital between 2005 and 2017. Inclusion criteria were adult patients with either PEEK or structural allograft, anterior plate fixation, and a minimum 2-year follow-up. Exclusion criteria were hybrid PEEK and allograft cases, additional posterior surgery, adjacent corpectomies, infection, tumor, stand-alone or integrated screw and cage devices, bone morphogenetic protein use, or lack of a minimum 2-year follow-up. Demographic variables, number of treated levels, interbody type (PEEK cage vs structural allograft), graft packing material, pseudarthrosis rates, revision surgery rates, subsidence, and cervical lordosis changes were collected. These data were analyzed by Pearson's chi-square test (or Fisher's exact test, according to the sample size and expected value) and Student t-test.
\end{abstract}

RESULTS A total of 168 patients (264 levels total, mean follow-up time $39.5 \pm 24.0$ months) were analyzed. Sixty-one patients had PEEK, and 107 patients had structural allograft. Pseudarthrosis rates for 1 -level fusions were 5.4\% (PEEK) and 3.4\% (allograft) ( $p>0.05$ ); 2-level fusions were 7.1\% (PEEK) and 8.1\% (allograft) ( $p>0.05$ ); and $\geq 3$-level fusions were $10 \%$ (PEEK) and $11.1 \%$ (allograft) $(p>0.05)$. There was no statistical difference in the subsidence magnitude between PEEK and allograft in 1-, 2-, and $\geq 3$-level ACDF ( $p>0.05)$. Postoperative lordosis loss was not different between cohorts for 1- and 2-level surgeries.

CONCLUSIONS In 1- and 2-level ACDF with plating involving the same number of fusion levels, there was no statistically significant difference in the pseudarthrosis rate, revision surgery rate, subsidence, and lordosis loss between PEEK cages and structural allograft.

https://thejns.org/doi/abs/10.3171/2019.9.SPINE19879

KEYWORDS anterior cervical discectomy and fusion; pseudarthrosis; PEEK cage; structural allograft; revision surgery; ACDF

$\mathrm{T}$ HE anterior cervical discectomy and fusion (ACDF) procedure has been used with both PEEK and structural allograft for degenerative cervical conditions. ${ }^{16}$ Although autologous iliac crest used to be a common graft material, it is associated with its own set of sequelae and complications. ${ }^{1}$ Structural allograft has been shown to be a viable alternative, with overall good outcomes, even though fusion rates may not be as good as iliac crest graft. ${ }^{8}$ Because of the modulus of elasticity, PEEK cages have come onto the spinal implant market as a substitute or alternative to structural allograft. $6,11,13,21$

Although there are a few direct comparisons between PEEK cages and structural allograft in ACDF, the reports are varied. Some manuscripts have reported similar

ABBREVIATIONS ACDF = anterior cervical discectomy and fusion; $B M P=$ bone morphogenetic protein; $\mathrm{DBM}=$ demineralized bone matrix.

SUBMITTED July 26, 2019. ACCEPTED September 26, 2019.

INCLUDE WHEN CITING Published online December 13, 2019; DOI: 10.3171/2019.9.SPINE19879. 
clinical outcomes, fusion rates, and subsidence.22 However, other studies have shown that using PEEK cages has a higher pseudarthrosis rate than using structural allograft.,12 We review our experience with plated ACDF with either PEEK or structural allograft with a minimum 2-year follow-up to report our findings on fusion rates, subsidence, reoperation rates, and lordosis change.

\section{Methods}

We retrospectively reviewed the $\mathrm{ACDF}$ cases performed by 2 attending neurosurgeons at our hospital between August 2005 and January 2017. With regard to choosing PEEK versus allograft, it was a matter of surgeon preference in deciding which interbody to choose. However, all surgeons involved in the study had used both PEEK cage and structural allograft, but there was no specific reason for choosing one over the other. Inclusion criteria were as follows: minimum 2-year follow-up with imaging, ACDF with either PEEK cage or allograft, surgery for degenerative conditions of the spine, age $\geq 18$ years, and anterior plate fixation. Exclusion criteria were as follows: additional posterior cervical surgery (staged or not), adjacent-level corpectomies, infection, tumor, trauma, stand-alone integrated screw and cage devices, bone morphogenetic protein (BMP) use, and hybrid constructs (both PEEK cages and allograft in the same patient). Patients who had cages with integrated fixation (either blades or integrated screws obviating the need for a plate) were all excluded; only patients with anterior cervical plating were included in this study. Patients had a maximum of $+5^{\circ}$ kyphosis because a larger kyphosis would also have received posterior instrumentation, excluding them from this study. Data collection included demographic variables, number of levels treated, interbody type (PEEK vs structural allograft), graft packing material (local autograft, demineralized bone matrix [DBM], or hybrid [DBM and local autograft]), pseudarthrosis rates, loss of lordosis, radiographic subsidence, and revision surgery rates for pseudarthrosis. The local autograft was all harvested using endplate shavings from the vertebral bodies or anterior osteophytes. Patients who had iliac crest graft were all excluded.

All postoperative 2-year images in this study were evaluated by at least 2 spine surgeons. Pseudarthrosis was counted if there was observation of motion on dynamic radiographs (change in vertebral body angulation or interspinous process distance), lucency through the fusion mass, the appearance of a halo around the screws, or implant failure that could be visualized on radiographs (Fig. 1). Thus, fusion was assessed by 2 independent spine surgeons, with a CT scan if available, and with dynamic radiographs assessing motion or stability of spinous process splaying. Only revision surgery for pseudarthrosis was recorded. Other causes unrelated to pseudarthrosis such as hematoma or infection were not included in the revision surgery rates.

To evaluate subsidence magnitude, we measured the distance from the midpoint of the upper endplate of the upper vertebral body to the midpoint of the lower endplate of the lower vertebral body spanning the fusion (Fig. 2A). These changes were noted from the initial postoperative

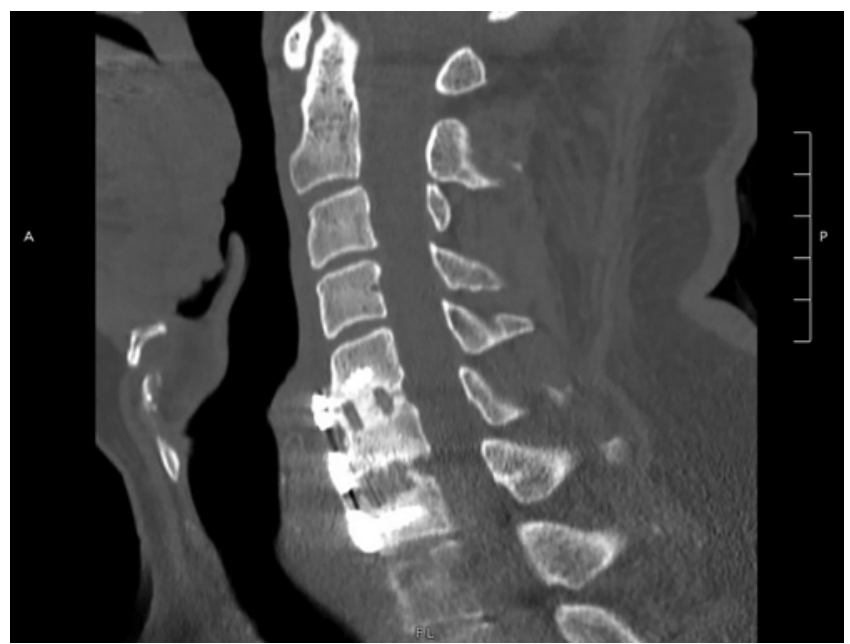

FIG. 1. A 2-year postoperative CT scan of a patient undergoing 2-level ACDF surgery, showing good fusion at C5-6 and bone graft absorption (pseudarthrosis) at C6-7.

radiograph and compared to the radiograph obtained at last follow-up. For the lordosis change after surgery, we measured the Cobb angle (from the superior endplate of the level above to the inferior endplate of the level below the fusion) at the last follow-up compared to the initial postoperative radiograph (Fig. 2B).

The collected data were statistically analyzed by Pearson's chi-square test or Fisher's exact test according to the sample size and expected value. Additionally, the t-test and Pearson's chi-square tests were used to determine demographic differences. A Pearson's correlation test was also used to correlate the pseudarthrosis rate and number of fused levels. All statistical analysis was processed using IBM SPSS Statistics 21.0 (IBM Corp.), and p values were considered significant if $<0.05$.

\section{Results}

A total of 168 patients who had undergone ACDF met inclusion criteria, with 264 levels fused. All 168 patients had a minimum of 2 years of follow-up (41 had CT scans, and 127 had radiographs), with a mean follow-up of 39.5 \pm 24.0 months, but 263 patients were excluded due to lack of the minimum 2-year follow-up, posterior cervical instrumentation, corpectomies with ACDF, stand-alone devices with integrated screws and blades, infection, tumor, trauma, iliac crest graft, or BMP use. Of the 168 patients, 61 (36.3\%) underwent fusion with PEEK, and 107 (63.7\%) underwent fusion with structural allograft. There was no significant difference in age, sex, and smoking status between the 2 groups. Of the entire cohort of 168 patients, $5(8.2 \%)$ with PEEK had pseudarthrosis, and $11(10.3 \%)$ with structural allograft had pseudarthrosis $(p>0.05)$. Of the 264 fusion levels, the 89 PEEK fusion levels had 6 pseudarthrosis segments (6.7\%), and in the 175 structural allograft levels, 13 pseudarthrosis segments $(7.4 \%)$ were observed ( $\mathrm{p}>0.05)$. Of the 89 PEEK levels, the average subsidence was $1.1 \pm 1.3 \mathrm{~mm}$ per level, and of the 175 structural allograft levels, the average subsidence was 0.9 

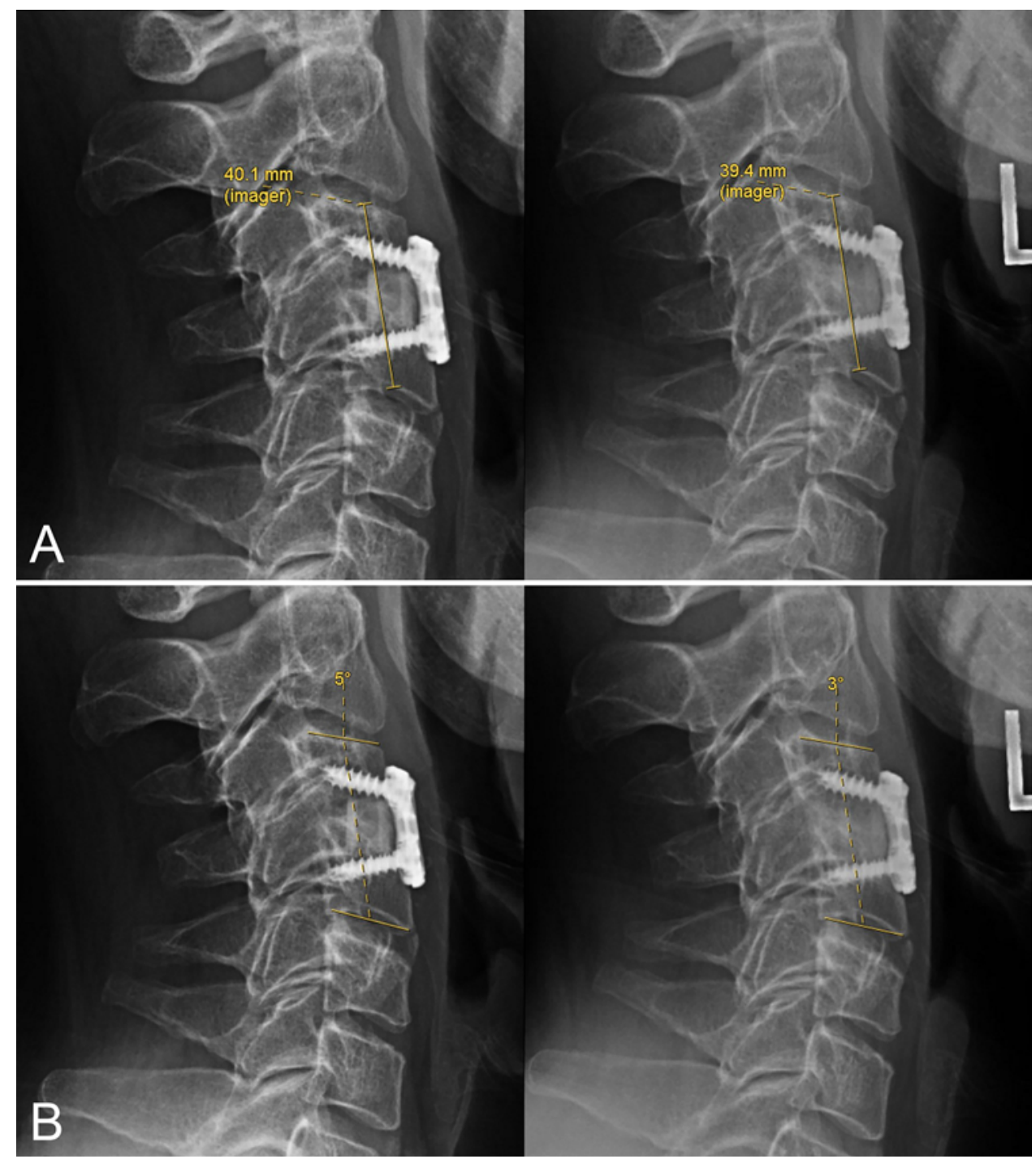

FIG. 2. A: Radiographs showing the method of measuring the intervertebral height in this study, from the midpoint of the upper endplate of the upper vertebral body at the treated level to the midpoint of the lower endplate of the lower vertebral body. The immediately postoperative radiograph is on the left and the last follow-up one is on the right. B: Radiographs showing the method of measuring the cervical lordosis loss in this study, which was represented by the difference between the Cobb angle of the treated level at the last follow-up and the Cobb angle immediately postoperatively. The immediately postoperative radiograph is on the left and the last follow-up one is on the right. Figure is available in color online only.

$\pm 1.1 \mathrm{~mm}$ per level $(\mathrm{p}>0.05)$. The total loss of lordosis was $1.5^{\circ} \pm 2.2^{\circ}$ in the PEEK cohort and $1.9^{\circ} \pm 2.1^{\circ}$ in the structural allograft cohort ( $\mathrm{p}>0.05)$. The overall pseudarthrosis, subsidence, and lordosis loss rates were not significantly different between the PEEK and structural allograft cohorts ( $p>0.05$ in both cohorts; Table 1).

\section{Single-Level ACDF}

Ninety-six patients underwent a single-level ACDF, with 37 (38.5\%) having a PEEK cage and 59 (61.5\%) having structural allograft. We did not detect a difference in the pseudarthrosis rates between the PEEK group (2/37, $5.4 \%)$ and the allograft group $(2 / 59,3.4 \%)(\mathrm{p}>0.05$; Table 2, Fig. 3). Moreover, none of the patients with single-level ACDF underwent revision surgery regardless of interbody type (Table 3). In addition, the type of graft used (autograft, DBM, or hybrid) did not statistically affect fusion rates in either the PEEK cohort or the structural allograft cohort (Fisher's exact test, $p>0.05$ in both cohorts; Table 4). The subsidence between PEEK $(1.0 \pm 1.0 \mathrm{~mm})$ and structural allograft $(0.9 \pm 1.1 \mathrm{~mm})$ was not different $(\mathrm{p}>$ 0.05 ) for single-level ACDF. The lordosis loss of PEEK $\left(1.3^{\circ} \pm 2.2^{\circ}\right)$ was also not different from that of structural allograft $\left(1.4^{\circ} \pm 2.1^{\circ}\right)(\mathrm{p}>0.05$; Table 5).

\section{Two-Level ACDF}

For the 52 patients undergoing 2-level ACDFs there were a total of 104 treated levels, with 42 (40.4\%) PEEK cages and $62(59.6 \%)$ structural allografts. The pseudarthrosis rate of the PEEK group $(3 / 42,7.1 \%)$ was similar 
TABLE 1. Demographic variables, overall pseudarthrosis rate, intervertebral height loss, and lordosis loss of all included ACDF cases, regardless of number of treated levels

\begin{tabular}{|c|c|c|c|c|}
\hline Variable & PEEK Cage & Structural Allograft & Total & $\mathrm{p}$ Value \\
\hline Patients & $61(36.3 \%)$ & $107(63.7 \%)$ & 168 & NA \\
\hline Surgery levels & $89(33.7 \%)$ & $175(66.3 \%)$ & 264 & NA \\
\hline Age, yrs & $53.5 \pm 12.3$ & $56.1 \pm 10.6$ & $55.2 \pm 11.3$ & 0.184 \\
\hline Female & $52(34.2 \%)$ & $100(65.8 \%)$ & 152 & \multirow{2}{*}{0.842} \\
\hline Male & $37(33.0 \%)$ & $75(67.0 \%)$ & 112 & \\
\hline Smoking status & $18 / 89(20.2 \%)$ & $41 / 175(23.4 \%)$ & $59 / 264(22.3 \%)$ & 0.555 \\
\hline Mean follow-up time, mos & $39.6 \pm 25.5$ & $39.4 \pm 23.3$ & $39.5 \pm 24.0$ & 0.935 \\
\hline Overall pseudarthrosis rate by patients & $5 / 61(8.2 \%)$ & $11 / 107(10.3 \%)$ & $16 / 168(9.5 \%)$ & 0.658 \\
\hline Overall pseudarthrosis rate by levels & $6 / 89(6.7 \%)$ & $13 / 175(7.4 \%)$ & $19 / 264(7.2 \%)$ & 0.838 \\
\hline Intervertebral height loss per treated level, $\mathrm{mm}$ & $1.1 \pm 1.3$ & $0.9 \pm 1.1$ & $1.0 \pm 1.2$ & 0.485 \\
\hline Lordosis loss per treated level, degrees & $1.5 \pm 2.2$ & $1.9 \pm 2.1$ & $1.8 \pm 2.2$ & 0.144 \\
\hline
\end{tabular}

NA $=$ not applicable

Values are expressed as either the mean \pm SD or the number of patients or procedures (\%).

to that of the structural allograft group $(5 / 62,8.1 \%)$ ( $\mathrm{p}>$ 0.05 ; Table 2, Fig. 3). For the revision surgery rate, 2 of the 3 PEEK pseudarthrosis patients underwent revision surgery, whereas none of 5 pseudarthrosis cases in the structural allograft group underwent revision surgery (Fisher's exact test, $\mathrm{p}>0.05$; Table 3). After further analyzing the subgroups based on packing material, there was no difference in fusion rates based on graft packing material in the structural allograft cohort (Fisher's exact test, $\mathrm{p}>0.05$; Table 4). With regard to subsidence, the PEEK cages subsided $1.2 \pm 1.6 \mathrm{~mm}$, and the structural allografts subsided $1.1 \pm 1.3 \mathrm{~mm}(\mathrm{p}>0.05)$. The PEEK cohort lost $2.0^{\circ} \pm 2.1^{\circ}$ of lordosis, and the structural allograft cohort lost $2.3^{\circ} \pm$ $2.4^{\circ}$ of lordosis $(p>0.05)$.

\section{ACDF of Three or More Levels}

For $\geq 3$-level ACDF, 20 patients were treated for a total of 64 levels fused. There were 10 levels (15.6\%) with PEEK cages and 54 levels (84.4\%) with structural allograft. The

TABLE 2. Comparison of PEEK cage and structural allograft in fusion and pseudarthrosis rate for different levels of ACDF

\begin{tabular}{|c|c|c|c|c|c|}
\hline \multirow{2}{*}{$\begin{array}{l}\text { Treated } \\
\text { Levels }\end{array}$} & \multirow{2}{*}{$\begin{array}{l}\text { Interbody } \\
\text { Device }\end{array}$} & \multicolumn{2}{|c|}{ Outcome } & \multirow[b]{2}{*}{ Total } & \multirow{2}{*}{$\begin{array}{c}p \\
\text { Value }\end{array}$} \\
\hline & & Fusion & Pseudarthrosis & & \\
\hline \multirow{3}{*}{ 1-level } & PEEK cage & $35(94.6 \%)$ & $2(5.4 \%)$ & 37 & \multirow{3}{*}{0.631} \\
\hline & $\begin{array}{l}\text { Structural } \\
\text { allograft }\end{array}$ & $57(96.6 \%)$ & $2(3.4 \%)$ & 59 & \\
\hline & Total & $92(95.8 \%)$ & $4(4.2 \%)$ & 96 & \\
\hline \multirow{3}{*}{ 2-level } & PEEK cage & $39(92.9 \%)$ & $3(7.1 \%)$ & 42 & \multirow{3}{*}{0.863} \\
\hline & $\begin{array}{l}\text { Structural } \\
\text { allograft }\end{array}$ & $57(91.9 \%)$ & $5(8.1 \%)$ & 62 & \\
\hline & Total & $96(92.3 \%)$ & $8(7.7 \%)$ & 104 & \\
\hline \multirow{3}{*}{$\geq 3$-level } & PEEK cage & $9(90 \%)$ & $1(10 \%)$ & 10 & \multirow{3}{*}{0.918} \\
\hline & $\begin{array}{l}\text { Structural } \\
\text { allograft }\end{array}$ & $48(88.9 \%)$ & $6(11.1 \%)$ & 54 & \\
\hline & Total & $57(89.1 \%)$ & $7(10.9 \%)$ & 64 & \\
\hline
\end{tabular}

pseudarthrosis rate of the PEEK group $(1 / 10,10 \%)$ was not statistically different from that of the structural allograft group $(6 / 54,11.1 \%)$ ( $>0.05$; Table 2, Fig. 3A). Moreover, different graft packing material did not result in statistically significantly different pseudarthrosis rates in either the PEEK cohort or the structural allograft cohort ( $p>0.05$ in both cohorts; Table 4). The only pseudarthrosis case in the PEEK group underwent revision surgery, but none of the 6 pseudarthrosis cases in the structural allograft group did; this difference was not statistically significant (Fisher's exact test, $\mathrm{p}>0.05$ ). There was no difference in the amount of subsidence between the PEEK group $(1.0 \pm 0.8 \mathrm{~mm})$ and the structural allograft group $(0.9 \pm 0.8 \mathrm{~mm})(\mathrm{p}>0.05$; Table 5). Although the sample size of the 2 groups was small and differed greatly (PEEK, 3 patients/10 levels; allograft, 17 patients/54 levels), the PEEK cage group lost less lordosis $\left(0.3^{\circ} \pm 2.2^{\circ}\right)$ than the structural allograft group $\left(2.1^{\circ} \pm 1.9^{\circ}\right)(\mathrm{p}<0.05$; Table 5).

\section{Discussion}

The ACDF has been an effective operation with good outcomes. ${ }^{3,16}$ Historically, tricortical iliac crest autograft was routinely used, $, 3,19$ but donor site morbidity resulted in other graft options being sought.,15 According to a recent survey, PEEK cages and structural allograft are the most widely used grafts for ACDF worldwide as an alternative to iliac crest. ${ }^{21}$ Structural allograft has been shown to be safe $^{17}$ with good clinical outcomes and decent fusion rates. ${ }^{5,8,10}$ PEEK is also considered a good spacer for spine surgery because of its biocompatible and corrosionresistant properties. ${ }^{6,18}$ Moreover, the modulus of elasticity of PEEK is similar to that of bone, ${ }^{4,9}$ which in theory may decrease the subsidence rates compared to metallic cages. ${ }^{2,20}$ In addition, the radiolucent property of PEEK allows for clearer visualization of fusion on radiographic imaging. However, these cages provide no osteoinduction or osteoconduction, and thus the PEEK cage itself can only function as a spacer, relying on graft material inside to induce fusion. ${ }^{14}$

With regard to previous studies, there are few direct 
A Pseudarthrosis Rate by Number of Treated Level(s) (\%)

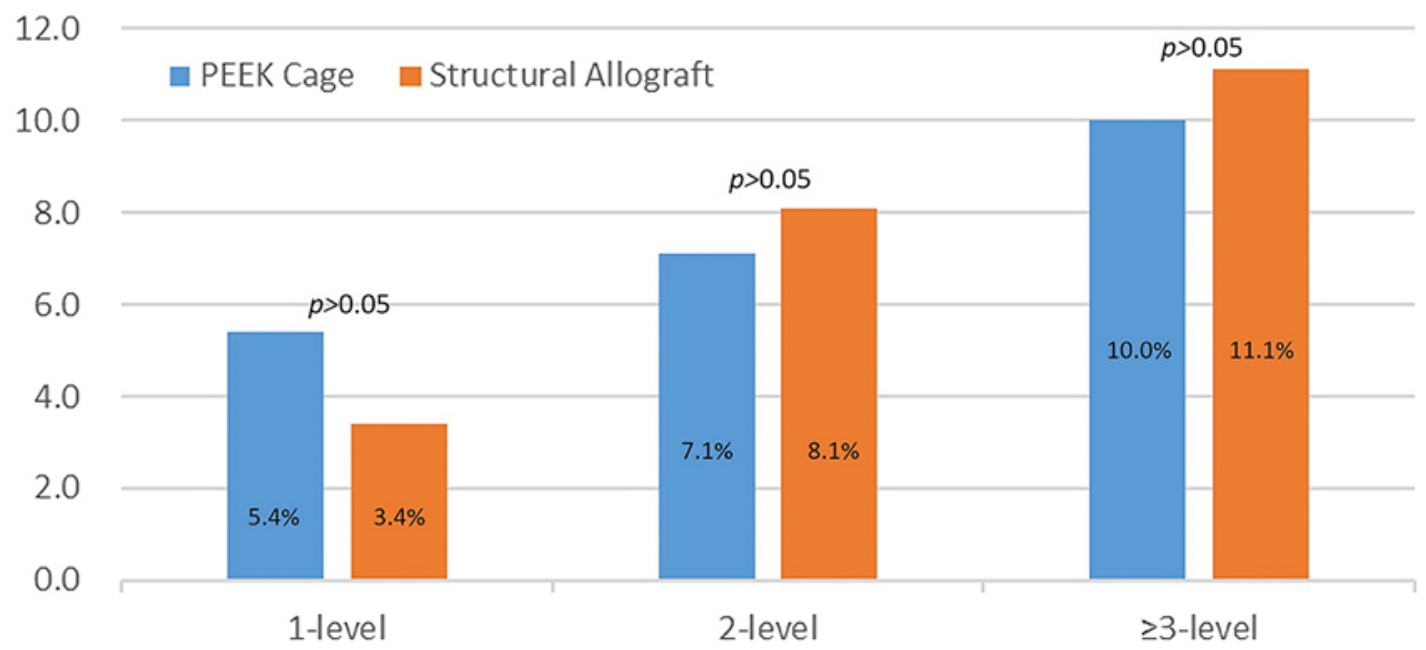

\section{B Pseudarthrosis Rate by Number of Patients (\%)}

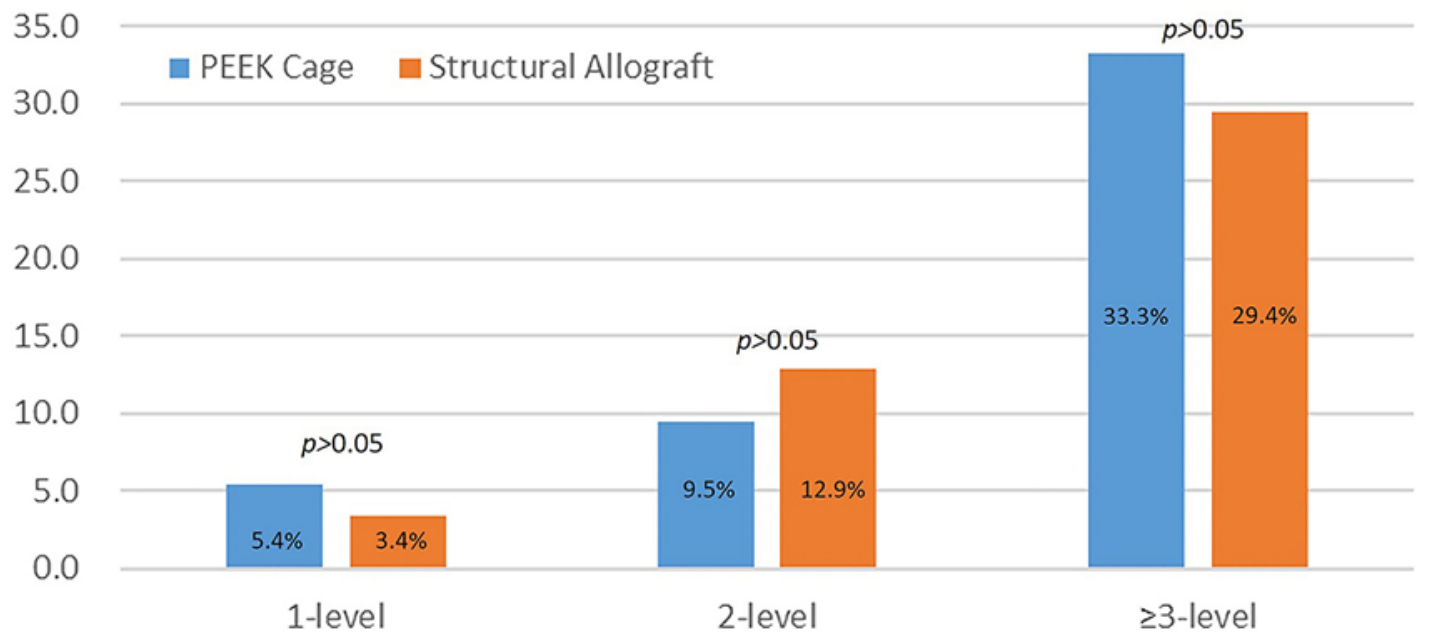

FIG. 3. A: Bar graph showing the pseudarthrosis rate between PEEK cage and structural allograft in 1-level, 2-level, and $\geq 3$-level ACDF, by the number of treated levels. B: Bar graph showing the pseudarthrosis rate between PEEK cage and structural allograft in 1-level, 2-level, and $\geq 3$-level ACDF, by the number of patients. Figure is available in color online only.

comparisons between PEEK and structural allograft used for ACDF. Yson et al. reported that subsidence rates between PEEK and allograft were comparable, but their study did not report on fusion rates. ${ }^{22}$ Krause et al. recently reviewed 127 patients (56 PEEK, 71 allograft) who underwent ACDF and had a minimum 1-year follow-up, and they found a much higher pseudarthrosis rate and revision surgery rate in the PEEK group compared to the structural allograft group. ${ }^{7}$ However, in their study, they only had 1 year of follow-up as a minimum. The minimum 2-year follow-up in our group may have accounted for noting more fusions observed in the PEEK cohort after 1 year, resulting in our observation of comparable fusion rates between the 2 cohorts. Moreover, $25 \%$ of their patients were smokers. In our study, although $22 \%$ of our patients were smokers, our spine center policy requires all smokers to stop smoking prior to fusion surgery. Because of this smoking cessation requirement prior to surgery, even though the patients may have been listed as smokers in the medical record, they are required to cease smoking prior to surgery. Thus, this may have accounted for our higher fusion rates in the PEEK cohort. Another factor that may have accounted for the higher pseudarthrosis rate in the study by Krause et al. is their use of integrated cage and screw or blade fixation in their PEEK cage surgeries. In our study, these patients were all excluded, and only patients with an anterior cervical plate were included. We excluded patients with stand-alone devices, integrated screw or blade cage devices, or fusion without plating. The ideal position of the screws was divergent in the sagittal plane at 
TABLE 3. Comparison of PEEK cage and structural allograft in revision surgery rate for different levels of ACDF

\begin{tabular}{|c|c|c|c|c|c|}
\hline Treated Levels & Interbody Device & Pseudarthrosis w/o RS & Pseudarthrosis w/ RS & Total & p Value \\
\hline \multirow{3}{*}{ 1-level } & PEEK cage & $2(100 \%)$ & 0 & 2 & \multirow{3}{*}{ NA } \\
\hline & Structural allograft & $2(100 \%)$ & 0 & 2 & \\
\hline & Total & $4(100 \%)$ & 0 & 4 & \\
\hline \multirow{3}{*}{ 2-level } & PEEK cage & $1(33.3 \%)$ & $2(66.7 \%)$ & 3 & \multirow{3}{*}{0.107 (Fisher's exact test) } \\
\hline & Structural allograft & $5(100 \%)$ & 0 & 5 & \\
\hline & Total & $6(75 \%)$ & $2(25 \%)$ & 8 & \\
\hline \multirow{3}{*}{$\geq 3$-level } & PEEK cage & 0 & $1(100 \%)$ & 1 & \multirow{3}{*}{0.143 (Fisher's exact test) } \\
\hline & Structural allograft & $6(100 \%)$ & 0 & 6 & \\
\hline & Total & $6(85.7 \%)$ & $1(14.3 \%)$ & 7 & \\
\hline
\end{tabular}

$\mathrm{RS}=$ revision surgery.

the uppermost and lowermost levels and convergent in the axial planes of all levels.

Pirkle et al. culled an insurance database and reported that PEEK cages in ACDF are associated with a higher nonunion rate $\left(5.32 \%\right.$ for cages vs $1.97 \%$ for allograft). ${ }^{12}$ However, a limitation of their study was that they only had a 1-year minimum follow-up. As discussed above, having the patients followed for up to 2 years may have resulted in a different observation. Second, by evaluating more than 6000 patients from an insurance database, they could not get the granularity in their study that is obtained when studies are carried out in specific institutions. For instance, it is unknown what the smoking status was in the patients, what graft material was used, or the numbers of integrated screw/plate design implanted in the study by Pirkle et al. because of the database design. Our fusion rates for structural allograft were comparable with historically reported fusion rates (1-level, 96.6\%; 2-level, 91.9\%; $\geq 3$-level, 88.9\%). Our fusion rates with PEEK cages were comparable for multilevel fusions, but lower for singlelevel ACDF (1-level, 94.6\%; 2-level, 92.9\%; 3-level, 90\%). Thus, although previous studies did show higher pseudarthrosis rates in PEEK cages and ACDF, these previous studies had only 1-year minimum follow-up and included integrated screw/plate and cage devices. Because these patients were all excluded in our study, this exclusion could have accounted for the different finding that we observed.

With regard to subsidence, we did not find a statistically significant difference in subsidence between PEEK and allograft in single-level or multilevel ACDF, consistent with the findings from Yson et al. ${ }^{22}$ Furthermore, the postoperative loss of lordosis between PEEK and structural allograft

TABLE 4. Classification statistics of cage types and filler types for different levels of ACDF

\begin{tabular}{|c|c|c|c|c|c|c|}
\hline \multirow[b]{2}{*}{ Treated Levels } & \multirow[b]{2}{*}{ Interbody Device } & \multirow[b]{2}{*}{ Filler Type } & \multicolumn{2}{|c|}{ Outcome } & \multirow[b]{2}{*}{ Total } & \multirow[b]{2}{*}{ p Value } \\
\hline & & & Fusion & Pseudarthrosis & & \\
\hline \multirow{6}{*}{ 1-level } & \multirow{3}{*}{ PEEK cage } & Autograft & $32(94.1 \%)$ & $2(5.9 \%)$ & 34 & \multirow{3}{*}{0.842 (Fisher's exact test) } \\
\hline & & DBM/hybrid & $3(100 \%)$ & 0 & 3 & \\
\hline & & Total & 35 & 2 & 37 & \\
\hline & \multirow{3}{*}{ Structural allograft } & Autograft & $53(98.1 \%)$ & $1(1.9 \%)$ & 54 & \multirow{3}{*}{0.164 (Fisher's exact test) } \\
\hline & & DBM/hybrid & $4(80.0 \%)$ & $1(20.0 \%)$ & 5 & \\
\hline & & Total & 57 & 2 & 59 & \\
\hline \multirow{6}{*}{ 2-level } & \multirow{3}{*}{ PEEK cage } & Autograft & $39(92.9 \%)$ & $3(7.1 \%)$ & 42 & \multirow{3}{*}{ NA } \\
\hline & & DBM/hybrid & 0 & 0 & 0 & \\
\hline & & Total & 39 & 3 & 42 & \\
\hline & \multirow{3}{*}{ Structural allograft } & Autograft & $56(93.3 \%)$ & $4(6.7 \%)$ & 60 & \multirow{3}{*}{0.156 (Fisher's exact test) } \\
\hline & & DBM/hybrid & $1(50 \%)$ & $1(50 \%)$ & 2 & \\
\hline & & Total & 57 & 5 & 62 & \\
\hline \multirow{6}{*}{$\geq 3$-level } & \multirow{3}{*}{ PEEK cage } & Autograft & $6(85.7 \%)$ & $1(14.3 \%)$ & 7 & \multirow{3}{*}{0.700 (Fisher's exact test) } \\
\hline & & DBM/hybrid & $3(100 \%)$ & 0 & 3 & \\
\hline & & Total & 9 & 1 & 10 & \\
\hline & \multirow{3}{*}{ Structural allograft } & Autograft & $43(89.6 \%)$ & $5(10.4 \%)$ & 48 & \multirow{3}{*}{0.646} \\
\hline & & DBM/hybrid & $5(83.3 \%)$ & $1(16.7 \%)$ & 6 & \\
\hline & & Total & 48 & 6 & 54 & \\
\hline
\end{tabular}


TABLE 5. The subsidence distance and lordosis loss at the last follow-up

\begin{tabular}{clccc}
\hline $\begin{array}{c}\text { Treated } \\
\text { Levels }\end{array}$ & $\begin{array}{c}\text { Postop Parameter Changes } \\
\text { per Treated Level }\end{array}$ & $\begin{array}{c}\text { PEEK } \\
\text { Cage }\end{array}$ & $\begin{array}{c}\text { Structural } \\
\text { Allograft }\end{array}$ & $\begin{array}{c}\mathrm{p} \\
\text { Value }\end{array}$ \\
\hline \multirow{2}{*}{ 1-level } & Intervertebral height loss, $\mathrm{mm}$ & $1.0 \pm 1.0$ & $0.9 \pm 1.1$ & 0.649 \\
\cline { 2 - 5 } & Lordosis loss, degrees & $1.3 \pm 2.2$ & $1.4 \pm 2.1$ & 0.916 \\
\hline \multirow{2}{*}{ 2-level } & Intervertebral height loss, $\mathrm{mm}$ & $1.2 \pm 1.6$ & $1.1 \pm 1.3$ & 0.859 \\
\cline { 2 - 5 } & Lordosis loss, degrees & $2.0 \pm 2.1$ & $2.3 \pm 2.4$ & 0.504 \\
\hline 3-lev- & Intervertebral height loss, $\mathrm{mm}$ & $1.0 \pm 0.8$ & $0.9 \pm 0.8$ & 0.637 \\
\cline { 2 - 5 } el & Lordosis loss, degrees & $0.3 \pm 2.2$ & $2.1 \pm 1.9$ & $0.028^{*}$ \\
\hline
\end{tabular}

Values are expressed as the mean $\pm S D$.

* Significant at $p<0.05$

in 1-level and 2-level ACDF was not significantly different. The sample size in the $\geq 3$-level ACDF cohort was too small to make a meaningful comparison. No significant kyphotic deformities were included in the present study. Patients with larger kyphosis (C2-7 Cobb angle more than $5^{\circ}$ kyphosis) would also have had posterior instrumentation, excluding them from our study; no patients in our study had posterior surgery. In addition, the ideal postoperative alignment would have been slightly lordotic.

With regard to graft material packed within both the PEEK cages and the structural allograft, we did not detect a statistically significant difference between graft types. However, our study may be underpowered to detect a difference. Our finding is consistent with the results of a systematic review by Zadegan et al., which showed noninferior results using DBM compared to autograft during $\mathrm{ACDF} .23$

There are limitations in our study. First, this is a retrospective, single-center study. A multicenter study would be more representative. Moreover, only 41 of 168 patients had CT scans. Thus, fusion was evaluated by radiographs primarily. Fusion was only evaluated by CT when available because CT scans were not done on every patient. Ideally, CT scans would have been used on all patients, but the costs and radiation exposure to the patient would have made routine CT on all patients impractical. However, all patients had flexion/extension and neutral films at the 2-year follow-up with a 2-surgeon independent review of the fusions. Thus, there were strict plain radiographic criteria for assessing fusion despite not having CT scans on every patient. In addition, although there were 168 patients, when broken down into subgroups the study may have been underpowered to detect differences with the smaller cohorts.

Another limitation of this paper is the lack of consistent bone density scores. Although it would have been ideal to have bone density scores for all patients, this was not universally available. However, previous reports comparing PEEK and structural allograft did not report bone density scores either.,12 A possible selection bias in our study was that although there were 431 patients with ACDF, only 168 of them met the minimum 2-year follow-up and did not have posterior instrumentation, corpectomies with ACDF, stand-alone devices with integrated screws or blades, tumor, infection, trauma, iliac crest graft, or BMP use. How- ever, this study's main focus was on fusion; we did not want to include patients without a 2-year follow-up because of the potential for inaccurate assessment of fusion rates with a shorter follow-up. Another selection bias was that some patients refused allograft due to cultural or religious reasons; however, we were not able to consistently identify which patients refused allograft because of these reasons. Moreover, the characteristics of the PEEK cages or structural allografts used in this study were not from one company; they were of various sizes and degrees of lordosis from different companies. The strengths of this study, however, are the minimum 2-year follow-up; the exclusion of the integrated screw/blade and cages; the strict criteria of only including patients with anterior plating; the strict inclusion criteria of only degenerative conditions; and the exclusion of trauma, corpectomies, and hybrid constructs.

\section{Conclusions}

In 1-level and 2-level ACDF with plating for degenerative conditions, there was not a detectable difference in pseudarthrosis rates, revision rate, subsidence, or lordosis loss between PEEK cage and structural allograft.

\section{References}

1. Armaghani SJ, Even JL, Zern EK, Braly BA, Kang JD, Devin CJ: The evaluation of donor site pain after harvest of tricortical anterior iliac crest bone graft for spinal surgery: a prospective study. Spine (Phila Pa 1976) 41:E191-E196, 2016

2. Cabraja M, Oezdemir S, Koeppen D, Kroppenstedt S: Anterior cervical discectomy and fusion: comparison of titanium and polyetheretherketone cages. BMC Musculoskelet Disord 13:172, 2012

3. Faldini C, Leonetti D, Nanni M, Di Martino A, Denaro L, Denaro V, et al: Cervical disc herniation and cervical spondylosis surgically treated by Cloward procedure: a 10-yearminimum follow-up study. J Orthop Traumatol 11:99-103, 2010

4. Gu YT, Jia LS, Chen TY: Biomechanical study of a hat type cervical intervertebral fusion cage. Int Orthop 31:101-105, 2007

5. Kao FC, Niu CC, Chen LH, Lai PL, Chen WJ: Maintenance of interbody space in one- and two-level anterior cervical interbody fusion: comparison of the effectiveness of autograft, allograft, and cage. Clin Orthop Relat Res (430):108-116, 2005

6. Kersten RF, van Gaalen SM, de Gast A, Öner FC: Polyetheretherketone (PEEK) cages in cervical applications: a systematic review. Spine J 15:1446-1460, 2015

7. Krause KL, Obayashi JT, Bridges KJ, Raslan AM, Than KD: Fivefold higher rate of pseudarthrosis with polyetheretherketone interbody device than with structural allograft used for 1-level anterior cervical discectomy and fusion. J Neurosurg Spine 30:46-51, 2018

8. Lee JC, Jang HD, Ahn J, Choi SW, Kang D, Shin BJ: Comparison of cortical ring allograft and plate fixation with autologous iliac bone graft for anterior cervical discectomy and fusion. Asian Spine J 13:258-264, 2019

9. Liao JC, Niu CC, Chen WJ, Chen LH: Polyetheretherketone (PEEK) cage filled with cancellous allograft in anterior cervical discectomy and fusion. Int Orthop 32:643-648, 2008

10. Miller LE, Block JE: Safety and effectiveness of bone allografts in anterior cervical discectomy and fusion surgery. Spine (Phila Pa 1976) 36:2045-2050, 2011

11. Niu CC, Liao JC, Chen WJ, Chen LH: Outcomes of interbody fusion cages used in 1 and 2-levels anterior cervical discec- 
tomy and fusion: titanium cages versus polyetheretherketone (PEEK) cages. J Spinal Disord Tech 23:310-316, 2010

12. Pirkle S, Kaskovich S, Cook DJ, Ho A, Shi LL, Lee MJ: Cages in ACDF are associated with a higher nonunion rate than allograft: a stratified comparative analysis of 6130 patients. Spine (Phila Pa 1976) 44:384-388, 2019

13. Seaman S, Kerezoudis P, Bydon M, Torner JC, Hitchon PW: Titanium vs. polyetheretherketone (PEEK) interbody fusion: meta-analysis and review of the literature. J Clin Neurosci 44:23-29, 2017

14. Shimizu T, Fujibayashi S, Yamaguchi S, Otsuki B, Okuzu Y, Matsushita T, et al: In vivo experimental study of anterior cervical fusion using bioactive polyetheretherketone in a canine model. PLoS One 12:e0184495, 2017

15. Silber JS, Anderson DG, Daffner SD, Brislin BT, Leland JM, Hilibrand AS, et al: Donor site morbidity after anterior iliac crest bone harvest for single-level anterior cervical discectomy and fusion. Spine (Phila Pa 1976) 28:134-139, 2003

16. Sugawara T: Anterior cervical spine surgery for degenerative disease: a review. Neurol Med Chir (Tokyo) 55:540-546, 2015

17. Tomford WW: Bone allografts: past, present and future. Cell Tissue Bank 1:105-109, 2000

18. Toth JM, Wang M, Estes BT, Scifert JL, Seim HB III, Turner AS: Polyetheretherketone as a biomaterial for spinal applications. Biomaterials 27:324-334, 2006

19. Vanek P, Bradac O, DeLacy P, Saur K, Belsan T, Benes V: Comparison of 3 fusion techniques in the treatment of the degenerative cervical spine disease. Is stand-alone autograft really the "gold standard?": prospective study with 2-year follow-up. Spine (Phila Pa 1976) 37:1645-1651, 2012

20. Wenz LM, Merritt K, Brown SA, Moet A, Steffee AD: In vitro biocompatibility of polyetheretherketone and polysulfone composites. J Biomed Mater Res 24:207-215, 1990

21. Yoon ST, Konopka JA, Wang JC, Youssef JA, Meisel HJ, Brodke DS, et al: ACDF graft selection by surgeons: survey of AOSpine members. Global Spine J 7:410-416, 2017
22. Yson SC, Sembrano JN, Santos ER: Comparison of allograft and polyetheretherketone (PEEK) cage subsidence rates in anterior cervical discectomy and fusion (ACDF). J Clin Neurosci 38:118-121, 2017

23. Zadegan SA, Abedi A, Jazayeri SB, Vaccaro AR, RahimiMovaghar V: Demineralized bone matrix in anterior cervical discectomy and fusion: a systematic review. Eur Spine J 26:958-974, 2017

\section{Disclosures}

Dr. Chan received support of a non-study-related clinical or research effort that he oversaw from Orthofix. Dr. Chou is a consultant for Medtronic and Globus, and he receives royalties from Globus. Dr. Mummaneni is a consultant for DePuy Synthes, Globus, and Stryker, and has direct stock ownership in Spinicity/ ISD. He receives support for a non-study-related clinical or research effort that he oversees from NREF and ISSG. He receives royalties from Thieme Publishing, Springer Publishing, and DePuy Synthes. He receives honoraria from Spineart.

\section{Author Contributions}

Conception and design: Wang, Chou, Mummaneni. Acquisition of data: Wang, Chang. Analysis and interpretation of data: Wang, Liu, Chan, Pennicooke. Drafting the article: Wang. Critically revising the article: Chou, Hirpara, Mummaneni. Reviewed submitted version of manuscript: Chou, Mummaneni. Statistical analysis: Wang. Administrative/technical/material support: Chou, Mummaneni. Study supervision: Chou, Mummaneni.

\section{Correspondence}

Minghao Wang: University of California, San Francisco, CA. wisewangmh@hotmail.com. 